\title{
A systematic review of population and community dietary interventions to prevent cancer
}

\author{
Margaret Thorogood ${ }^{1}$, Iveta Simera ${ }^{2}$, Elizabeth Dowler ${ }^{3}$, Carolyn Summerbell ${ }^{4}$ and Eric Brunner ${ }^{5}$ \\ ${ }^{1}$ Warwick Medical School, University of Warwick, Coventry CV4 7AL, UK \\ ${ }^{2}$ Centre for Statistics in Medicine, University of Oxford, Linton Road, Oxford OX2 6UD, UK \\ ${ }^{3}$ Department of Sociology, University of Warwick, Coventry CV4 7AL, UK \\ ${ }^{4}$ School of Health, University of Teesside, Middlesbrough TS1 3BA, UK \\ ${ }^{5}$ Department of Epidemiology and Public Health, University College London, Gower Street Campus, 1-19 Torrington Place, \\ London WCIE 6BT, UK
}

\begin{abstract}
Diet is an important factor in the causation of cancer. Previous systematic reviews of one-to-one interventions to encourage dietary change have found that such interventions can achieve modest improvements in diet. However, such interventions are resource intensive and unlikely to be good value for money at a population level. Interventions that address groups, communities or whole populations may be less resource intensive and effect change in a wider population. We report a systematic review of such interventions. We set wide inclusion criteria, including before-andafter studies and studies with a non-randomized comparison group as well as randomized trials. We found eighteen studies based in the community, seventeen based on worksites, five based in churches and one based in a supermarket. Interventions which targeted fruit and vegetable intake were most likely to be successful, particularly in worksites and churches. There was also evidence of small positive effects on reducing fat intake in worksites and churches. Overall the communitybased interventions showed little effect. The studies included in the present review were generally poorly reported. Dietary changes are reported in the relatively short-term studies reviewed here but may not be sustained in the long term. The effects that we have identified are small but the reach is potentially very wide, in some cases as wide as a whole country. The cost effectiveness of such strategies remains to be evaluated.
\end{abstract}

Cancer prevention: Dietary interventions: Population interventions

\section{Introduction}

It has been estimated that diet accounts for $30 \%$ of all cancers in developed countries and up to $20 \%$ in developing countries. It is important, therefore, to understand how dietary interventions can help to reduce the risk of cancer. A recent review by Key et al. ${ }^{1}$ has summarized the evidence on the dietary causation of cancer. The review concluded that dietary factors which convincingly increase cancer risk include overweight and obesity, intake of alcoholic beverages, aflatoxin and highly salted (Chinese-style) fish. High intakes of preserved meat and red meat, salt-preserved foods and salt, and consumption of very hot drinks and foods probably increase some kind of cancers. Dietary factors which probably reduce cancer risk include fruit and vegetables $(\mathrm{F} \& \mathrm{~V})$. Their recommendations in relation to cancer prevention are listed in Table 1 and, in most respects, are very similar to recommendations for reducing the risk of vascular diseases, including IHD and stroke.

The potential for reducing cancer and vascular risk through effecting changes in diet at community or population level is considerable. The question is how best to achieve the desired shift in dietary patterns and food-related behaviours, in terms of 'what interventions work?'. Many evaluations of healthy eating interventions have been published and there are already a number of systematic reviews ${ }^{2-11}$.

A recent Cochrane Collaboration review concludes that individual-based interventions, such as dietary advice offered to healthy adults, can achieve modest improvements in diet and cardiovascular risk factors ${ }^{12}$. However, to our knowledge, no recent systematic review has been carried out of programmes aimed at group-, community- and population-level intervention, and it is these interventions that are the subject of the systematic review described here.

\footnotetext{
Abbreviation: $F \& V$, fruit and vegetable.

* Corresponding author: Dr Margaret Thorogood, fax +44 247657 4509, email margaret.thorogood@warwick.ac.uk
} 
Table 1. Dietary recommendations in relation to cancer prevention ${ }^{1}$

\begin{tabular}{ll}
\hline 1 & Maintain BMI in range of $18 \cdot 5-25 \mathrm{~kg} / \mathrm{m}^{2}$, and avoid weight \\
gain in adulthood \\
Engage in regular physical activity \\
Consumption of alcoholic beverages is not recommended: if \\
consumed, do not exceed two units per d (one unit is \\
equivalent to approximately $10 \mathrm{~g}$ alcohol) \\
Minimize exposure to aflatoxin in foods \\
Highly salted fish should only be eaten in moderation, \\
especially during childhood. Overall consumption of salt- \\
preserved foods and salt should be moderate \\
Have a diet which includes at least $400 \mathrm{~g}$ total fruit and \\
vegetables per d \\
Meat: moderate consumption of preserved meat (for \\
example, sausages, salami, bacon, ham etc) and red \\
meat (for example, beef, pork, lamb). Poultry and fish \\
(except highly salted fish) have been studied and found not \\
to be associated with increased cancer risk \\
Do not consume foods or drinks when they are at a very hot \\
(scalding hot) temperature
\end{tabular}

\section{Methods}

The objective of the present review was to systematically identify and critically appraise published systematic reviews and research papers reporting interventions that evaluate group, community and population dietary prevention programmes for cancer prevention. We carried out a systematic search for relevant papers, extracted details of the papers into an agreed proforma and then synthesized the results in a narrative form. Where possible we also provided a quantitative summary of effect sizes.

\section{Included studies}

We included studies which evaluated group- or populationlevel dietary interventions to reduce cancer risk, which report results at least 6 months from baseline, and which employed one of the following study designs:

(a) randomized controlled trials;

(b) quasi-experimental studies and studies with a comparison group;

(c) uncontrolled before-and-after studies (pre-test-posttest cohort studies).

The geographical focus of the present review is North America, Europe, Australia and New Zealand.

Group- or population-level interventions may contain elements which are aimed at individuals, for example, takehome leaflets or recipes, and we included studies of interventions where there was some activity aimed at individuals if the main focus of the intervention was at group level. The intervention design strategy had to focus on changes at group, community or population level, such that sampling, selection of control groups (if present), and the main delivery of the intervention were at a group level. We included studies carried out in the general population (in towns, regions, countries), local communities, churches, workplaces, catering facilities and retail outlets. We did not include programmes delivered only through healthcare or school facilities. The 'group' may be opportunistic (for example, workplace), or self-selected (for example, church members) or geographic (all households living within an administrative area). Dietary interventions may also be targeted at groups defined by socio-economic or demographic characteristics, for example, a particular ethnic group, age group, income band or type of housing.

\section{Types of participants}

We included studies with healthy adult participants (age $>16$ years) or communities where children were part of a household. We excluded studies targeting individuals at increased or high risk only (for example, cardiovascular patients, obese patients, cancer patients) or children only (school settings).

\section{Types of interventions}

We included studies with any population- or communitybased intervention encouraging dietary change believed to prevent cancer. We used the dietary recommendations for cancer prevention listed in Table 1, and included any interventions that targeted at least one of those recommendations. Studies with multiple interventions aiming to influence factors other than diet (for example, smoking, physical activity, lifestyle changes) were included if they provided a clear description of activities relating to the nutrition component and sufficient dietary outcome data. We excluded interventions aimed solely at reducing obesity, but where weight reduction was a part of a multiple intervention including other dietary interventions related to reducing the risk of cancer we included the study.

\section{Outcome measures}

In the present review we report only on those outcomes of the interventions that are related to dietary change to prevent cancer. We also aimed to include information on cancer incidence and on the costs of interventions but we did not find any such information reported. The outcome measures that we identified were of two types: independently measured outcomes (such as sales data from a canteen) and self-reported data (such as information from a FFQ). Some studies report a wide range of outcomes, but most of the data we found focus on one or more of four dietary outcomes relating to cancer prevention: consumption of $\mathrm{F} \& \mathrm{~V}$, fat, fibre and red meat. The present review therefore focuses on these four outcomes.

\section{Literature search strategy}

We identified studies through systematic searching of electronic databases. We searched MEDLINE, EMBASE, Cochrane Library, CINAHL, PsychINFO, CAB Health, Social Science Index, Eric, SIGLE, Health Technology Assessment database, the Database of Promoting Health Effectiveness Reviews (DoPHER), Department of Health data and King's Fund database (HMIS) and Health Development Agency database (HDA website and Health Education Authority publication). As earlier good-quality reviews had searched the literature up to 1995 , we limited 
our searches to the period January 1994 to August 2005. A combination of subject headings (MESH) and free text terms (including alternative spellings) was used for all areas. No language restrictions were imposed. We did not undertake hand searching of any journals. We contacted experts in the field for information about new or unpublished projects. We checked the reference lists of selected papers for further studies. Records identified from searches were downloaded and managed using EndNote bibliographic software.

\section{Selection of studies}

Two reviewers independently screened all identified titles and, where available, abstracts for potential relevant studies. Two reviewers then independently evaluated each full text paper against predefined inclusion criteria, using an in/out form'. Differences between reviewers were resolved by discussion or in consultation with a third reviewer.

\section{Data extraction}

Once a list of included studies was agreed, two reviewers (not necessarily the same individuals who had included the studies at the previous stage) independently extracted data from the included studies using a standard form. We extracted the following details:

(a) study design;

(b) description of study settings and population (including data on measures of deprivation);

(c) description of all intervention and control programmes, including any theoretical framework, medium of intervention, and its duration;

(d) outcomes;

(e) measurement tools;

(f) data analysis, attrition and survey response rates, number of outcome assessments, length of follow-up, and any negative or adverse effects.

When there were not enough data for our purposes we contacted the authors for further information. If a study was published in more than one paper, we retrieved data from all available papers. Any disagreement between reviewers was resolved by discussion.

\section{Quality evaluation}

Two reviewers independently evaluated the methodological quality of studies, which included:

(a) for randomized controlled trials - method and unit of randomization, unit of analysis, clarity of description of methodology, including sampling for surveys, analysis method, attrition and survey response rate;

(b) for studies with a comparison group - unit of analysis, clarity of description of methodology including sampling for surveys, group comparability, analysis method, attrition and survey response rate;

(c) for before-and-after studies - clarity of description of methodology, before-and after-data reported for all groups on all outcomes.

\section{Data analysis}

We grouped studies according to their settings. The mode of analysis varied with study design. Where data were provided for more than one time point, we included only the results from the longest follow-up.

Randomized controlled trials and studies with a comparison group. The net effect was calculated as the difference between the change in the control group and the change in the intervention group. Outcomes were treated as continuous variables. All the randomized trials identified had been cluster randomized and appropriately analysed.

Meta-analysis was only possible in one case: for $\mathrm{F} \& \mathrm{~V}$ intake in worksite studies. Weighted mean differences and 95\% CI were produced. The Cochrane Collaboration software RevMan 4.2 (Metaview) was used to perform the analysis. The sign of the mean change for both the intervention and control groups has been changed so the direction of effect always shows the change favouring intervention on the left. Where the standard deviation of changes was not reported in a paper, we used the method recommended in the Cochrane Collaboration Handbook ${ }^{13}$ to make allowance for within-participant correlation from baseline to follow-up measurements, and estimated the standard deviation of the change. In a few cases even this was not possible and the studies appear on the graphs with the note that the weighted mean difference is not estimable. Because of substantial heterogeneity the summary statistic was calculated using a random-effects model.

When meta-analysis was not possible the net effect was calculated for individual studies and displayed graphically on forest plots, without a summary statistic. The number of participants $(n)$ given on the forest plots represents the number of individuals analysed in the various studies.

Uncontrolled before-and-after studies. We report the net effect as the difference between the follow-up measurement and the baseline value.

\section{Results}

We identified 19570 titles and considered 227 abstracts potentially eligible for inclusion. After assessment of the full papers ten systematic reviews and forty-nine primary studies were selected. A further eight primary studies were excluded during data extraction or following correspondence with the authors, leaving forty-one studies in the review (Fig. 1).

\section{Earlier systematic reviews}

We identified ten systematic reviews, which systematically searched databases using predefined inclusion and exclusion categories and which evaluated nutrition interventions in various settings including communities, workplaces, supermarkets and catering. One important source is a series of reviews published by the former UK Health Education Authority covering dietary intervention in the general population $^{3}$, workplaces ${ }^{5}$, minority ethnic groups ${ }^{7}$, elderly individuals ${ }^{4}$ and women of childbearing age ${ }^{6}$. Table 2 shows 


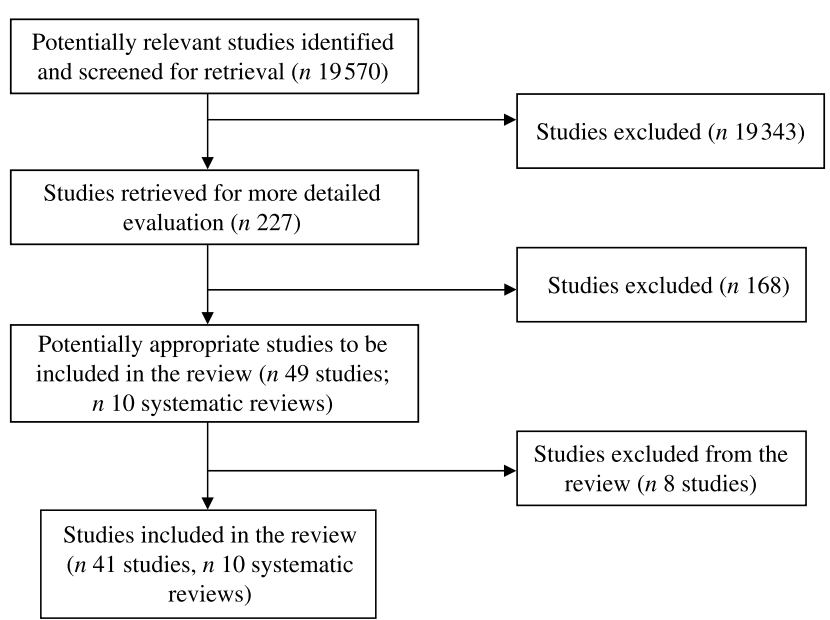

Fig. 1. Progress through the stages of a review.

the number of studies in each of the systematic reviews that consider interventions in groups, communities or whole populations.

The review by Roe et al. $^{3}$ summarizes the results of seventy-six interventions to promote healthy eating among the general population published between 1985 and 1996. The studies employed a wide range of intervention methods, target populations and outcome measures. The authors comment on the serious limitations of design, description of methodology and reporting of outcomes in many studies. The review includes sixteen evaluations of community interventions: ten large-scale multi-factorial before-andafter studies (including The North Karelia Project, Pawtucket Heart Health Program, Stanford Five-City Project and Minnesota Heart Health Project) and six randomized trials of intensive dietary interventions in smaller populations. The majority of the interventions (twelve of the sixteen studies) were based on a theoretical framework, mainly using social learning theory (seven of the sixteen studies). Change in fat intake is reported in ten of the sixteen studies. Six studies reported a decrease in fat consumption in the range of 5-10\% of energy and four studies found no difference in fat intake. F\&V consumption is reported in only one study, which did not find any positive effect.
The review included eight studies in supermarket settings, of which four were considered good-quality studies involving twenty to forty stores per study, and two of those showed a positive effect on food purchases or sales. There was little or no follow-up after the end of interventions, and from the limited evidence available it appeared that interventions only had an effect for as long as the intervention was in place.

Ten studies evaluated interventions in catering settings, all judged as mediocre quality. Positive effects were reported in sales of F\&V (one study), decreased sales of confectionery and crisps when moved away from tills (two studies), and increased sales of low-fat meals and salads when labelled with appropriate signs (five studies). Pointof-purchase promotion led to an increase in sales of 2-12\% but the effect generally lasted only as long as the intervention was in place. The longer-term effect on food choices was not assessed.

Roe et al. ${ }^{3}$ argued that the following features of interventions were associated with the most sustained positive effect on diet-related outcomes: a content which focused only on diet, or on diet and exercise; an intervention strategy based on theoretical frameworks rather than simple information giving; some degree of personalization of intervention characteristics; provision of feedback on individual changes in behaviour; multiple contacts over a substantial period of time; interpersonal support. In the supermarket and catering settings, the greatest effects were reported with the use of simple signs identifying healthier choices, food composition changes and changes in food availability.

A systematic review of health promotion interventions in the workplace includes fifty outcome evaluations published up to $1997^{5}$. Fifteen of the fifty included studies were judged to be sound, of which six targeted healthy eating. Three of the six studies found no beneficial effect on fat intake or overall dietary habits. Two studies reported a decrease in fat consumption and increase in $\mathrm{F} \& \mathrm{~V}$ intake at 12 months' follow-up. The authors of the review could not identify any clear trends in effectiveness in relation to certain types of interventions.

White et al. ${ }^{7}$ summarize the literature on interventions in individuals from minority ethic groups. There were two community-wide dietary programmes which both used a quasi-experimental design with a minimum of 1 year of

Table 2. Number of studies evaluating interventions at group, community or population level aiming at dietary change in each systematic review

\begin{tabular}{lrcccc}
\hline Reference & Total & $\begin{array}{c}\text { Community } \\
\text { or population }\end{array}$ & Worksite & Church & $\begin{array}{c}\text { Retail } \\
\text { or supermarket }\end{array}$ \\
\hline Roe et al. $(1997)^{3}$ & 34 & 16 & 10 & - & 8 \\
Peersman et al. $(1998)^{5}$ & 6 & - & 6 & - & - \\
${\text { White et al. }(1998)^{7}}_{\text {Glanz et al. }(1996)^{2}}^{11}$ & 4 & 4 & - & - & - \\
Janer et al. $(2002)^{11}$ & 10 & - & 10 & - & - \\
Ciliska et al. $(2000)^{9}$ & 7 & - & 7 & - & - \\
Bowen \& Beresford $(2002)^{10}$ & 15 & 15 & - & - & - \\
Brug et al. (1999) & 33 & 12 & 16 & 1 & - \\
Fletcher \& Rake (1998) $^{4}$ & 8 & - & - & - & - \\
${\text { Van Teijlingen et al. }(1998)^{6}}^{6}$ & 14 & 14 & - & - & - \\
\hline
\end{tabular}


follow-up. One intervention to increase low-fat milk consumption was ineffective. An intervention to decrease fat consumption was partly effective. The reviewers concluded that there is only limited and inconclusive evidence for the effectiveness of community-wide interventions.

Three other reviews concentrate on worksite health promotion programmes. Glanz et $a .^{2}$ reviewed ten education programmes relating to nutrition published between 1980 and 1995. Six studies used group education: either alone (two studies), in combination with individual counselling (two studies) or in combination with cafeteria programmes (two studies). Four studies were solely cafeteria based. Only one of the ten studies randomized worksites. The authors of the review commented that it was impossible to determine whether any observed positive changes had been the results of interventions, of selfselection or self-reporting bias, or of secular trends in general populations.

A review of worksite interventions targeting major cancer risk factors included nutritional interventions, and included both individual and group interventions ${ }^{11}$. The aims of included interventions were commonly to increase consumption of fruits, vegetables and high-fibre foods, or to decrease fat intake. Statistically significant increases in vegetable intake were observed in six of seven relevant studies. An increase in vegetable servings per $\mathrm{d}$ is reported in three of the seven studies, with ranges from 0.09 to 0.19 servings. Five of the studies also reported on fruit intake, and four found statistically significant increases, ranging from 0.11 to 0.24 servings per $d$. In three studies reporting on total $\mathrm{F} \& \mathrm{~V}$ intake, increases ranged from 0.18 to 0.5 servings per $d$. Ten studies reported changes in fat intake and six of these found a statistically significant fall in intake. However, the size of the falls was small; the largest fall reported is $3.0 \%$ energy from fat. An increase in fibre intake ranging from 0.005 to $0.406 \mathrm{~g} / 1000 \mathrm{~kJ}(0.02$ to $1.7 \mathrm{~g} /$ $1000 \mathrm{kcal})$ was observed in three out of five relevant trials. Worksite trials involving food environmental interventions, such as changes in the worksite canteen or vending machines, were no more effective than those without such environmental components. An increased duration of intervention, multiple contacts with participants, tailored interventions, incentives, and continuous support were all seen to increase effectiveness, but the reviewers commented that the data were not consistent.

Ciliska et $a .^{9}{ }^{9}$ reviewed fifteen studies of communitybased interventions aiming to increase $\mathrm{F} \& \mathrm{~V}$ consumption, including two worksite-based interventions, and one community-based programme focused on adults. The two worksite interventions achieved positive results in at least one reported outcome. The first trial found a statistically significant difference in overall $\mathrm{F} \& \mathrm{~V}$ consumption $(P<0.001)$; the intervention group achieved an increase of 0.2 servings per $d$ compared with the increase of 0.02 servings per $d$ in the control group. The second trial reported an increase in vegetable consumption in the intervention group by $6 \cdot 8$ servings per month compared with a fall by 1.6 servings per month in the control group $(P<0.02)$. The only community-based programme included ${ }^{14}$ did not report any positive changes. The authors of the review concluded that the most effective interventions gave clear messages about increasing F\&V consumption; incorporated multiple strategies that reinforced the messages; involved the family; were more intensive; were provided over a longer period of time, rather than one or two contacts; and were based on a clear theoretical framework.

A systematic review of dietary interventions published up to 2001 included thirty-eight interventions focused on groups of adults rather than individuals. Fourteen of these studies also met the inclusion criteria and were included in the present review. Of the thirty-eight studies, sixteen were based in worksites, and twelve in the community or general population. There were also four point-of-purchase studies, four primary care-based studies, one study targeting religious organizations and one study targeting families ${ }^{10}$. The reviewers did not place any restrictions on the design of included studies. Consistent positive changes were observed in most of the worksite studies, but the effect size was often small, and follow-up was short term. Other community settings, such as religious organizations and grocery stores, had mixed records of success. The limitations of study designs and evaluation methods prevented the authors of the review from drawing any firm conclusions.

Brug et al. ${ }^{8}$ summarized limited inconclusive evidence on computer-tailored nutrition education from the findings of eight studies.

None of these systematic reviews reached firm conclusions. Most interventions that were reviewed employed complex intervention strategies and a variety in evaluation designs, making it difficult to synthesize the data. However, there are some characteristics of successful interventions that are noted repeatedly in the reviews, and these are summarized in Table 3. The use of a theoretical framework as a basis of intervention activities is often discussed. Roe et $a .^{3}{ }^{3}$ stated that an intervention model incorporating behavioural theories and goals rather than one based on the provision of information is more likely to produce sustained effect on diet-related outcomes. Ciliska et al. ${ }^{9}$ also concluded that the most effective interventions to increase F\&V consumption in the USA were based on a theoretical framework, while Bowen $\&$ Beresford $^{10}$ note the lack of information on the use of theoretical frameworks in individual studies.

\section{Primary studies}

We included forty-one primary studies. Table 4 shows the country of origin and setting of the interventions.

Table 3. Characteristics of successful interventions as identified in the systematic reviews

An intervention that focused only on diet, or diet and exercise

Delivery of clear messages with multiple strategies to reinforce them

Some degree of intervention personalization to match individual characteristics

Provision of feedback to individuals on their changes in behaviour

A longer duration of intervention, with multiple contact with participants

Provision of incentives, and continuous support

Simple signs identifying healthier choices, changes in food availability and composition, point-of-purchase display policies in supermarket and catering settings 
Table 4. Country of origin and settings of included primary studies (Number of studies)

\begin{tabular}{lccccc}
\hline Country & Total & $\begin{array}{c}\text { Community } \\
\text { or population }\end{array}$ & Worksite & Church & $\begin{array}{c}\text { Retail } \\
\text { or supermarket }\end{array}$ \\
\hline USA & 25 & 8 & 11 & 5 & 1 \\
The Netherlands & 4 & 3 & 1 & - & - \\
UK & 3 & 2 & 1 & - & - \\
Canada & 3 & 2 & 1 & - & - \\
Australia & 2 & 1 & - & - & - \\
New Zealand & 1 & - & 1 & - & - \\
Norway & 1 & 1 & 17 & 5 & - \\
Denmark & 1 & - & 1 & - & 1 \\
Czech Republic & 1 & 18 & & & - \\
Total & 41 & & & & - \\
\hline
\end{tabular}

The majority of studies, twenty-eight $(68 \%)$, were carried out in North America ${ }^{14-40}$ (DJ Bowen, personal communication), ten $(24 \%)$ were carried out in Europe ${ }^{41-50}$ and three $(7 \%)$ in Australia and New Zealand ${ }^{51-53}$. Eighteen studies targeted healthy adults in the general population ${ }^{14-17,26-28,33,37,39,41-46,49,51}$. Seventeen studies targeted worksite employees ${ }^{18,19,21-23,25,29,31,32,34,35,38,47,48,50,52,53}$. Five studies targeted adult church members ${ }^{20,30,36,54}$ (DJ Bowen, personal communication) and one study was carried out in a food retail setting ${ }^{24}$. The intervention mechanisms employed included: educational sessions; cooking demonstrations; point-of-purchase displays; brochures, posters and other printed materials; videos; mass media advertising and educational programmes. Dietary outcomes reported included self-reported intake of fat, fibre, $\mathrm{F} \& \mathrm{~V}$, red meat; various behavioural scores related to healthy eating and sales data from supermarkets and worksite cafeterias. Table 5 summarizes the main results.

\section{Community or population studies}

Twelve of the eighteen interventions in the general population are non-randomized studies with a comparison group $^{15,26-28,33,39,41,43-45,49,51}$, five use a before-and-after evaluation design ${ }^{14,17,37,42,46}$, and one study is a clusterrandomized controlled trial ${ }^{16}$, where community is the unit of randomization and analysis. There are three state or nationwide studies: two assessing the impact of programmes promoting $\mathrm{F} \& \mathrm{~V}$ consumption in California ${ }^{17}$ and in the whole of the $\mathrm{USA}^{37}$, and one evaluating HeartBeat Wales ${ }^{44}$. The most commonly set dietary goals, apart from 'improving overall dietary behaviour' which featured in seven studies, were a decrease in fat consumption (five studies) and an increase in $\mathrm{F} \& \mathrm{~V}$ consumption (three studies). Studies varied greatly in the length of their intervention programmes and follow-up periods. The most common activities were the use of printed materials, supermarket events such as store tours, food product promotion, purchase coupon distribution, food labelling, cooking demonstrations, distribution of recipes, educational sessions, and engagement of the community through community leaders and local businesses. Mass media were widely used, including local newspapers, television and radio.
Fruit and vegetable intake. Very few studies provide details of what was included in the definition of $F \& V$ or the size of one serving. Changes in $\mathrm{F} \& \mathrm{~V}$ consumption are reported in six studies ${ }^{14,16,17,37,46,51}$. Three studies used a before-and-after design ${ }^{17,37,46}$ and report change in servings per d. Foerster et al. ${ }^{17}$ report the 2-year results of the Californian '5 a Day for Better Health' campaign promoting consumption of $\mathrm{F} \& \mathrm{~V}$. There was no significant change in combined $\mathrm{F} \& \mathrm{~V}$ consumption, although intake of vegetables increased by 0.2 servings per $\mathrm{d}(P<0.05)$, while fruit intake fell by a non-significant $0 \cdot 1$ servings per $d$. Stables et $a l .{ }^{37}$ report a 6-year evaluation of the national US ' 5 a Day for Better Health' F\&V promotion, which found an increase of 0.23 servings per d $(P=0.007)$. Wrigley et al. ${ }^{46}$ assessed the impact of a new supermarket on $F \& V$ consumption in a deprived community. There was no overall increase in $\mathrm{F} \& \mathrm{~V}$ consumption, although there was an increase in $\mathrm{F} \& \mathrm{~V}$ consumption in the $45 \%$ of respondents who had switched to using the new store (an increase of $0 \cdot 23$ servings per $\mathrm{d} ; P=0.03$ ).

Three studies report changes in scores based on $\mathrm{F} \& \mathrm{~V}$ consumption. Two 5-year community-based interventions ${ }^{16}$ report no significant effect in one community and a significant fall in $\mathrm{F} \& \mathrm{~V}$ consumption $(P<0.01)$ in the other community, in comparison with control communities. A 5-year intervention in a low-income rural area in Missouri, USA had no significant effect on the percentage of respondents consuming five or more portions per $\mathrm{d}^{14}$. A 2-year Heart Health Programme in a rural community in Victoria, Australia also had no effect on consumption of either fruit or vegetables ${ }^{51}$.

Fat intake. Seven studies report changes in fat intake. An intervention in California focused on the community and included education campaigns and initiatives in grocery stores in two communities. There were seven comparison communities. The researchers report no significant decrease in percentage of energy from fat ${ }^{16}$. Three non-randomized studies with comparison groups, all from the Netherlands ${ }^{41,43,49}$, report fat intake using different scoring systems. There was no significant difference in fat consumption in Maastricht after 3 years of a complex multifactorial intervention which included encouraging a reduction in fat intake ${ }^{49}$. The 'Fat Watch' campaign in Alkmaar used a variety of activities mainly based on written mass media information but also using events such as 
Table 5. Summary of results for the main dietary outcomes*

\begin{tabular}{|c|c|c|c|c|}
\hline Intervention setting. . & Community and population studies & Worksite studies & Church studies & $\begin{array}{l}\text { Retail } \\
\text { and super- } \\
\text { market } \\
\text { studies }\end{array}$ \\
\hline \multicolumn{5}{|l|}{ F\&V intake } \\
\hline F\&V (servings/d) & $\begin{array}{l}\text { Three studies (B-A). Two studies } \\
\text { with NS findings. One study found } \\
\text { increase of } 0.23 \text { servings/d }\end{array}$ & $\begin{array}{l}\text { Eight RCT (eleven interventions). Results pooled in a meta-analysis } \\
\text { (random-effects model), WMD } 0.18(95 \% \mathrm{Cl} 0.04,0 \cdot 31) \\
\text { servings/d; all but one study achieved results in a positive } \\
\text { direction }\end{array}$ & $\begin{array}{l}\text { Three studies (two RCT, one } \\
\text { Comp). Increase in a range } \\
\text { of } 0.13-0.18 \text { to } 0.85 \text { ser- } \\
\text { vings } / \mathrm{d}\end{array}$ & $\begin{array}{l}\text { One study } \\
\text { (RCT); } \\
\text { NS find- } \\
\text { ings }\end{array}$ \\
\hline F\&V (scores) & One study (RCT); NS findings & - & - & - \\
\hline $\begin{array}{l}\text { Number of individ- } \\
\text { uals consuming five } \\
\text { or more servings } \\
\text { per } d\end{array}$ & One study (B-A); NS findings & - & - & - \\
\hline $\begin{array}{l}\text { Percentage of indi- } \\
\text { viduals changing } \\
\text { towards healthy } \\
\text { diet }\end{array}$ & One study (Comp); NS findings & - & - & - \\
\hline \multicolumn{5}{|l|}{ Fat intake } \\
\hline Fat (\% energy) & $\begin{array}{l}\text { One study (RCT) (two interventions); } \\
\text { NS findings }\end{array}$ & $\begin{array}{l}\text { Three studies (two RCT, one Comp). One study (Comp) with NS } \\
\text { findings. Two studies (RCT) with decrease of } 0.37 \text { to } 1 \%\end{array}$ & Two studies (RCT); NS findings & - \\
\hline Fat $(\mathrm{g} / \mathrm{d})$ & - & $\begin{array}{l}\text { Three studies. One study (RCT) with negative effect }- \text { significant } \\
\text { increase of } 0.7 \mathrm{~g} / \mathrm{d} \text { with intervention. One study (RCT) with NS } \\
\text { findings. One study (Comp) with decrease of } 1.3 \mathrm{~g} / \mathrm{d}\end{array}$ & $\begin{array}{l}\text { One study (RCT); decrease of } \\
5.8 \mathrm{~g} / \mathrm{d}\end{array}$ & - \\
\hline Fat (various scores) & $\begin{array}{l}\text { Three studies (Comp). One study } \\
\text { with decrease in fat intake of } 0.9 \\
\text { points. Two studies with NS find- } \\
\text { ings }\end{array}$ & $\begin{array}{l}\text { Three studies (six interventions). One study with decrease with the } \\
\text { intervention. Two studies (five interventions) with NS findings }\end{array}$ & One study (RCT); NS findings & - \\
\hline \multicolumn{5}{|c|}{ 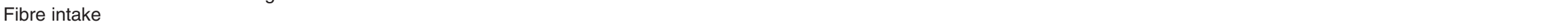 } \\
\hline Fibre $(\mathrm{g})$ & One study (RCT); NS findings & - & - & - \\
\hline Fibre $(\mathrm{g} / 1000 \mathrm{kcal})$ & - & $\begin{array}{l}\text { Two studies (RCT) with increase of } 0.13-0.50 \mathrm{~g} / 1000 \mathrm{kcal}(0.03- \\
0.12 \mathrm{~g} / 1000 \mathrm{~kJ})\end{array}$ & One study (RCT); NS findings & - \\
\hline Fibre intake (score) & - & - & One study (RCT); NS findings & - \\
\hline Red meat intake & $\begin{array}{l}\text { Two studies (one RCT, one Comp); } \\
\text { NS findings }\end{array}$ & - & - & - \\
\hline $\begin{array}{l}\text { Red meat (servings/ } \\
\text { week) }\end{array}$ & - & One study (B-A); NS findings & - & - \\
\hline 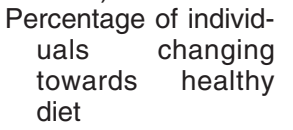 & - & One study (B-A); NS findings & - & - \\
\hline
\end{tabular}

F\&V, fruit and vegetables; B-A, before-and-after study; RCT, randomized controlled trial; WMD, weighted mean difference; Comp, study with comparison group.

* The intervention effect is given as the difference in change between the intervention and control group (for RCT and Comp), or the difference between pre- and post-study measurements (for B-A studies). Only significant changes are quoted. 
supermarket tours to encourage a reduce intake of fat. The evaluation found no difference in fat consumed between the intervention and control communities at the 10-month follow-up ${ }^{43}$. Another intervention, The Healthy Bergeyk programme, involved a multi-factorial health promotion initiative in which healthy eating was one of four targets. Again, the intervention design used a variety of activities mainly based on written mass media information and also used small group activities. There was a significantly greater $(P<0.001)$ fall in the 'fat score' in the intervention community compared with the control community ${ }^{41}$.

Fibre intake. The intervention in California described earlier also reported fibre intake in the intervention and control communities and found no statistically significant difference ${ }^{16}$.

Red meat intake. The intervention in California described earlier also reported red meat intake in the intervention and control communities and found no statistically significant difference $^{16}$. There was no difference in frequency of eating red meat between control and intervention communities in a study of intervention to decrease high-fat food intake in South Carolina, $\mathrm{USA}^{15}$.

\section{Worksite studies}

Ten of the seventeen studies set in worksites were randomized controlled trials, with worksite as the unit of randomization $^{18,22,23,29,31,34,35,38,50,52}$. Four studies used non-randomized comparison groups ${ }^{19,21,47,53}$, and three used a before-andafter design ${ }^{25,32,48}$. One study included fewer than 100 participants $^{38}$, while five included more then 2000 workers $18,23,34,35,52$. In three studies the participants were mostly women, while eight studies involved mostly men, and the rest involved roughly equal numbers of men and women. In eight studies the participants are described as being mainly in blue-collar occupations ${ }^{21,22,29,31,32,34,38,53}$. Three studies describe participants as mainly white-collar workers ${ }^{25,47,50}$, and employees in six studies are mixed socio-economic status.

There was frequent use of printed materials (for example, posters, brochures, leaflets), educational sessions and presentations, self-help materials, various activities (games, contests), worksite cafeteria events (displays, promotions, menu changes) and availability of healthy vending machine choices. Many interventions used peer leaders. The most common dietary goals were overall improvements in diet (eight studies), increased consumption of F\&V (seven studies), and decreased consumption of fat (six studies). The most frequently used method of assessing dietary intake was a FFQ. The duration of the intervention programmes varied from 3 months to more than 1 year.

Fruit and vegetable intake. Eight randomized controlled trials, with eleven intervention arms, evaluated interventions to increase consumption of $\mathrm{F} \& \mathrm{~V}$ measured in servings per $\mathrm{d}$. We have summarized the results of these trials in a metaanalysis, which shows an increase in consumption of 0.18 servings/d. Only one study, a large Australian trial, does not report an increase in consumption ${ }^{51}$ (JM Simpson, personal communication). The smallest trial recruited only thirty-three fire-fighters and was an outlier ${ }^{38}$, so we performed a sensitivity analysis without this study. The overall effect did not change dramatically (Fig. 2).

One study compared consumption in servings per $\mathrm{d}$ at an intervention and control worksite and reported a significantly greater increase in the proportion of respondents reporting two to three daily servings of vegetables, but no difference in fruit consumption at the intervention worksite $^{53}$. Two studies used a before-and-after design to evaluate interventions ${ }^{32,48}$. One small study of a single worksite found a small $(0.25)$ but significant increase in servings of F\&V at 9 months ${ }^{32}$, while another, larger, study of five worksites found significant increases in the sales of $\mathrm{F} \& \mathrm{~V}$ (g per customer) in the works canteens at all sites ${ }^{48}$.

One study considered the impact of an award scheme for workplace canteens that encouraged healthy eating (The Heartbeat Award scheme). The authors compared four work canteens that were given the award with two that were refused it. Employees in the successful workplaces reported an increase in fruit consumption in comparison with the two unsuccessful workplaces ${ }^{47}$.

Some studies assessed F\&V intake separately ${ }^{29,31,34,50}$. The results of these studies were also pooled in a metaanalysis. The summary results showed an increase in fruit consumption of 0.19 servings per $d$ and vegetable consumption of $0 \cdot 17$ servings per d (Fig. 3).

Fat intake. Nine studies report changes in fat intake expressed either as percentage of energy ${ }^{21,23,34}$, $g$ per $\mathrm{d}^{18,19,31}$ or through various fat scores ${ }^{50,52,53}$ (JM Simpson, personal communication). We have not performed a metaanalysis because of the small number of trials and the differences in study designs. Mean differences in individual studies and $95 \%$ CI intervals are shown in Fig. 4. The largest evaluation, the Working Well trial ${ }^{23}$, reports a decrease in fat consumption of $0.37 \%$ energy, while the second largest trial, 'Next step' ${ }^{34}$, reports a decrease of $1 \%$ in fat consumption.

One study evaluated an initiative to reduce the fat content of dishes offered in the canteen of one workplace and found no significant differences in sales figures for the modified dishes $^{25}$. One study considered the impact of The Heartbeat Award scheme on fat intake and found a reduction in the consumption of fried foods and an increase in consumption of low-fat milk in the four workplaces given an award compared with the two who failed to win an award, but no other significant changes in fat consumption ${ }^{47}$.

Fibre intake. Both of the trials that considered fibre intake reported an increased intake in the intervention worksites (Fig. 5).

Red meat intake. A small American intervention aiming at dietary change and smoking cessation in one worksite reports no significant difference in read meat intake ${ }^{32}$. The evaluation of the Heart Beat award scheme, described earlier, found no effect on meat consumption ${ }^{47}$.

\section{Church studies}

All five church-based interventions were carried out in the $\mathrm{USA}^{20,30,36,54}$ (DJ Bowen, personal communication). Four of 


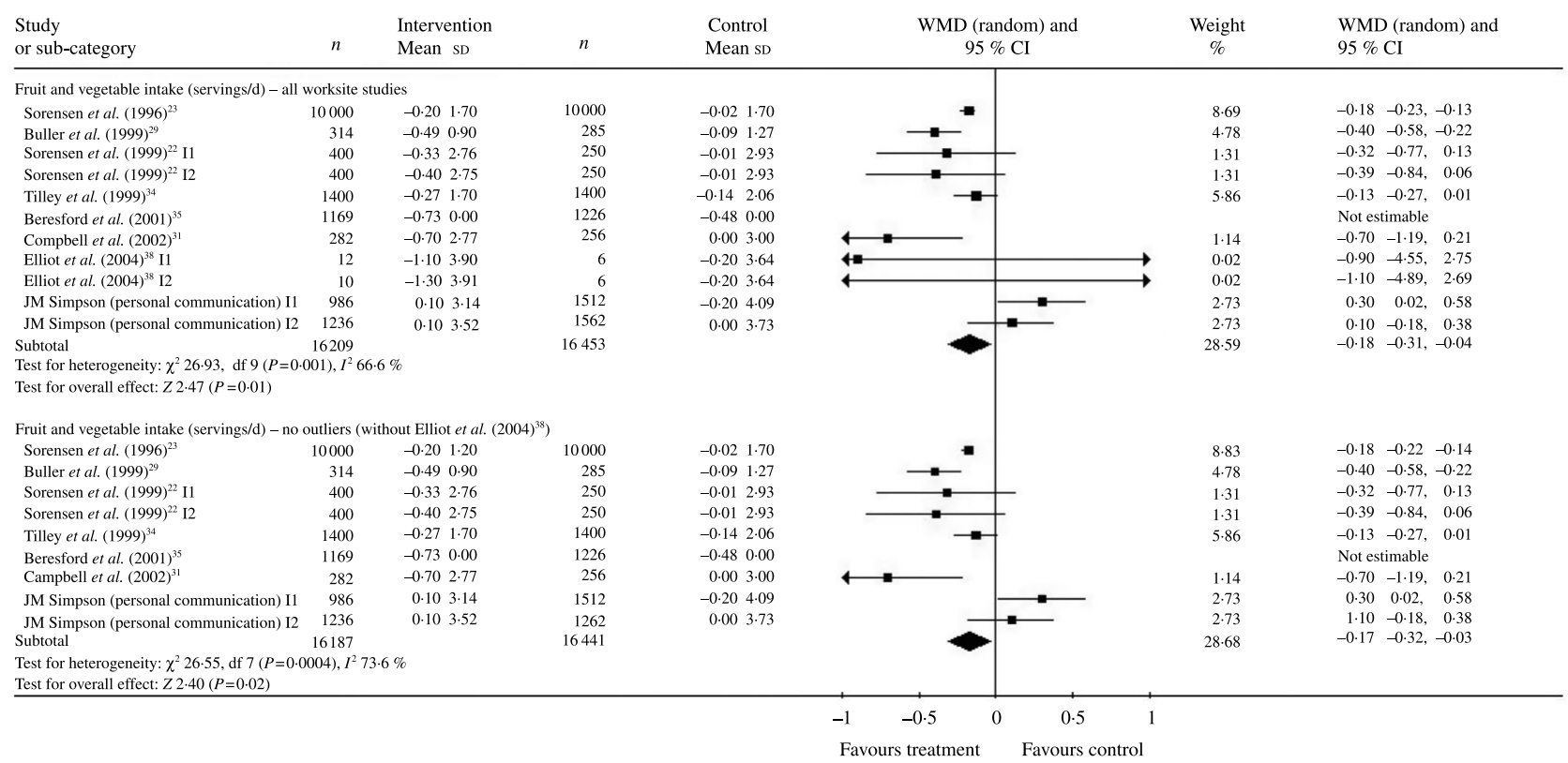

Fig. 2. Worksite studies. Fruit and vegetable intake (servings per d). WMD, weighted mean difference; I1, intervention 1; I2, intervention 2.

them took place in African-American churches, while the remaining one took place in a predominantly non-Hispanic White population. Three of the studies are randomized controlled trials. One trial ${ }^{54}$ (DJ Bowen, personal communication) randomized forty religious organizations and included more then 2000 participants, the second ${ }^{40}$ recruited participants from fifteen churches and included about 1000 participants. The third trial ${ }^{36}$ randomized sixteen churches and included about 500 participants. A non-randomized intervention with a comparison group ${ }^{30}$ was based in ten US counties with a high proportion of minority ethnic population. The intervention used data collected from 2500 respondents. A smaller before-and-after study ${ }^{20}$ involved four churches in North Florida, with about 370 participants. The majority of the participants in all the studies were women.

Fruit and vegetable intake. In one intervention that lasted 20 months, counties in South Carolina, USA, were randomized to control or intervention. In each intervention county, five African-American churches participated.

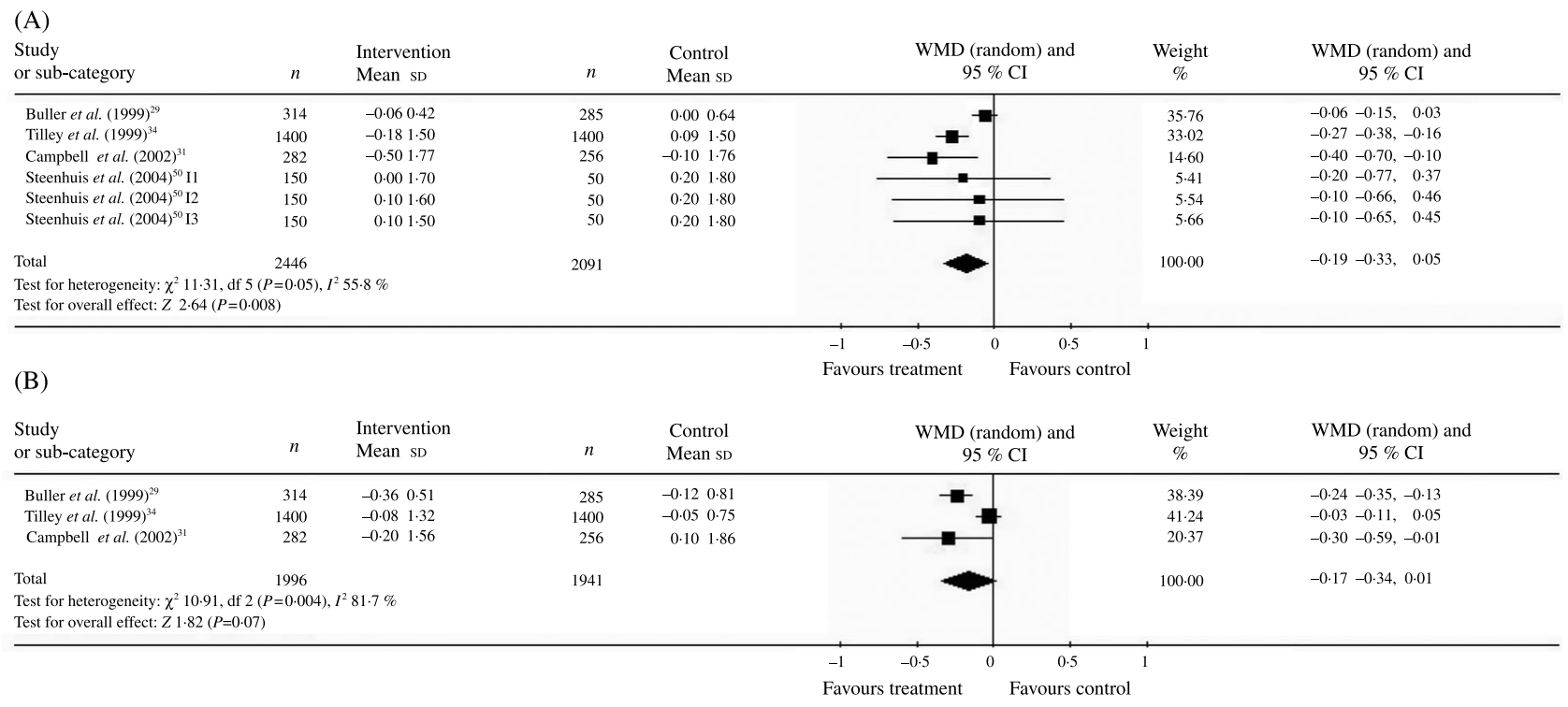

Fig. 3. Worksite studies. Fruit intake (A) and vegetable intake (B), analysed separately (servings per d). WMD, weighted mean difference; I1, intervention $1 ;$ I2, intervention 2; I3, intervention 3. 


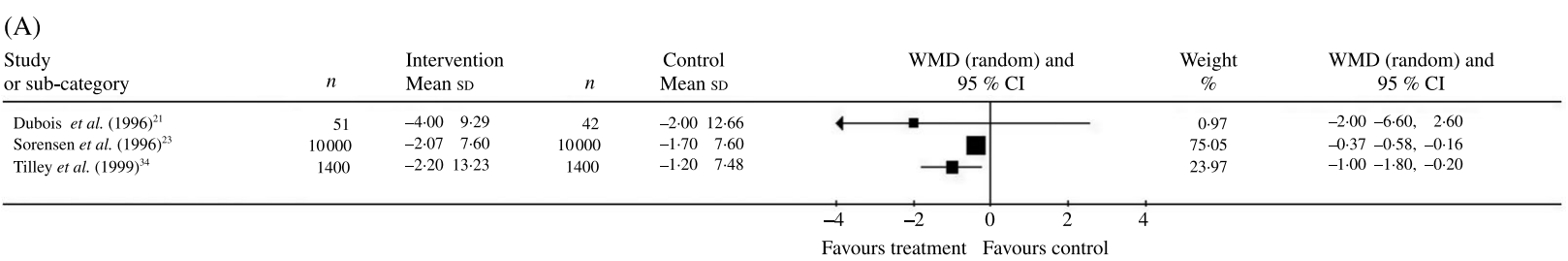

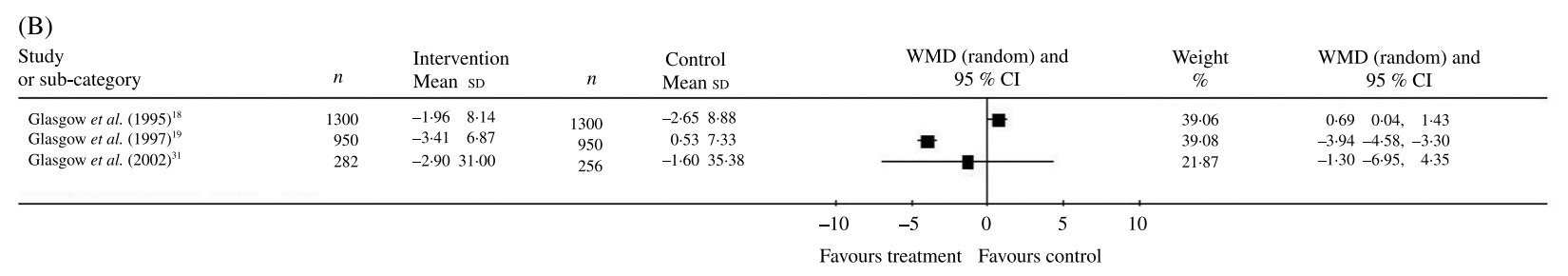

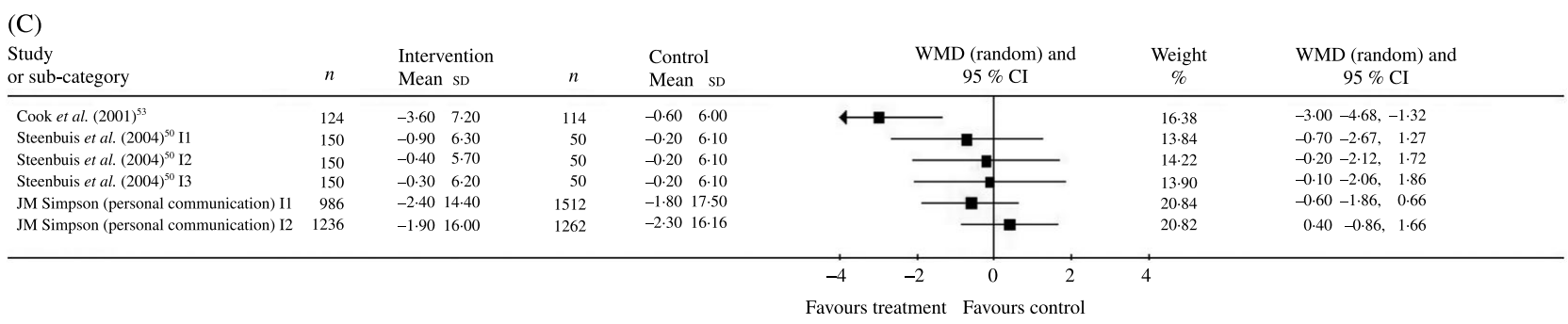

Fig. 4. Worksite studies: fat intake. (A) Fat intake (\% energy), (B) fat intake (g/d), (C) fat intake (various fat scores). WMD, weighted mean difference; I1, intervention 1; I2, intervention 2; I3, intervention 3.

Community coalitions, consisting of church members, grocers and farmers, were formed and organized activities promoting F\&V consumption. After 2 years the consumption of F\&V was higher in the intervention group by 0.85 (SE $0 \cdot 12)$ servings per $d$ than in the control group $(P<0.0001)^{30}$. The 'Body and Soul' intervention was evaluated in a cluster-randomized trial where AfricanAmerican churches were the unit of randomization. The intervention consisted primarily of church-wide nutrition activities, distribution of self-help materials and motivational interviewing. At a 6-month follow-up, intervention participants showed significantly greater F\&V intake; the adjusted post-test difference was 1.4 servings per $\mathrm{d}$, the corresponding estimated effect size $0 \cdot 18$ servings per d $(P<0.05)^{39}$. The 'Eating for a Healthy Life' project randomized forty predominantly white religious organizations. The 9-month intervention included interpersonal support, mailings, motivational messages on healthy eating, social activities, healthy eating sessions and print advertisements. At 12 months there was an increase of 0.13 servings of $\mathrm{F} \& \mathrm{~V} /$ individual per $\mathrm{d}$ in the intervention group $(P=0.051)^{54}$ (DJ Bowen, personal communication). Fig. 6 summarizes the findings.
Fat intake. The 'Eating for a Healthy Life' project $^{54}$ (DJ Bowen, personal communication) reported a statistically significant decrease of 0.05 points $(P=0.004)$ in a fat summary score in the intervention group compared with the control group, but no statistically significant difference in fat as a percentage of energy. 'Project Joy',36 randomized African-American churches to one of three interventions, developed in partnership with lay church members and investigators. A 'standard behavioural' intervention included motivational sessions, individual results of baseline screening, and nutrition and physical activity sessions. In the second intervention this was supplemented by a spiritual component, including group prayers. The participants in the 'standard behavioural' group spontaneously added a spiritual component to their activities, so there was little difference between these two interventions. The third (control) self-help group involved personalised feedback from baseline screening, and a list of personal goals, together with healthy eating and physical activity printed materials. At 1-year follow-up, the intervention groups had both reduced their fat intake by $8.1 \mathrm{~g} / \mathrm{d}$ while the selfhelp group had reduced theirs by only $2 \cdot 3 \mathrm{~g} / \mathrm{d}(P=0.025)$. The study investigators faced problems in the initial

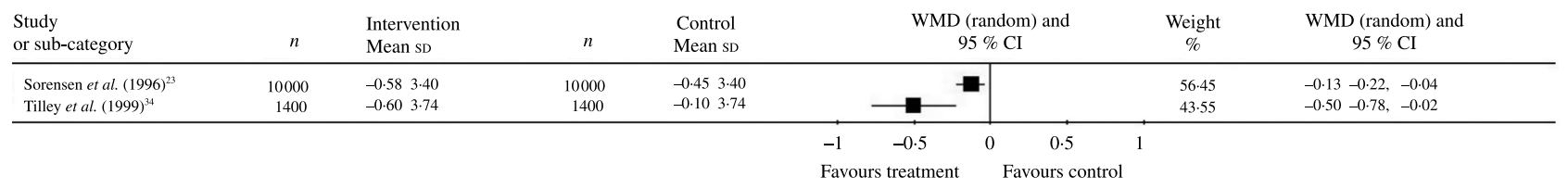

Fig. 5. Worksite studies. Fibre intake (g/1000 kcal). WMD, weighted mean difference. 


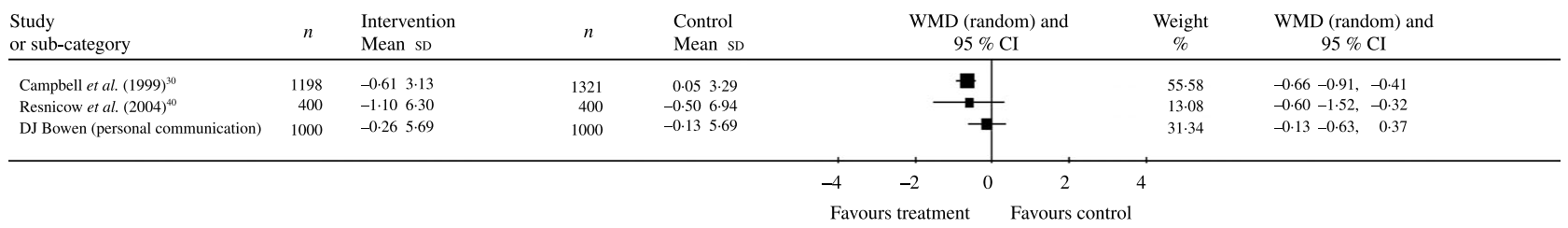

Fig. 6. Church studies. Fruit and vegetable intake (servings per d). WMD, weighted mean difference.

randomization phase, when most of the church leaders indicated a discomfort with the randomization process and wanted to be told the outcome of the randomization before they would agree to church enrolment. Fig. 7 summarizes the findings.

Fibre intake. The 'Eating for a Healthy Life' project reported an increase in fibre consumption by 0.06 of summary score scale in the intervention group when compared with the control $(P<0.001)$ (DJ Bowen, personal communication). The authors also assessed fibre intake by $24 \mathrm{~h}$ recall, and reported an increase of $0 \cdot 311 \mathrm{~g} / 1000 \mathrm{~kJ}(1.3 \mathrm{~g} / 1000 \mathrm{kcal})$ in the intervention group compared with the control. Fig. 8 illustrates the findings.

Red meat intake. No church-based study provided data on red meat intake.

\section{Retail and supermarket studies}

One study evaluated a supermarket point-of-purchase intervention $^{24}$. Eight supermarkets in Iowa, USA, were randomized to either an 8-month intervention promoting F\&V consumption or no intervention. The intervention consisted of flyers that identified $\mathrm{F} \& \mathrm{~V}$ on sale, gave recipes, menu ideas, and a store coupon towards the purchase of any fruit or vegetable. Store displays and food demonstrations supported the promotion. F\&V consumption was assessed at 1-year follow-up in the sample of 120 shoppers in each store. No statistically significant differences between the intervention and control groups were found. Fig. 9 illustrates the findings.

\section{Discussion and conclusions}

We have identified and reviewed forty-one evaluations of population- or community-based dietary interventions published since 1994 plus ten systematic reviews published since 1996. The present review shows that dietary changes are achievable by means of programmes aimed at populations, communities and groups in a variety of settings. At a nationwide level, the US ' 5 a Day for Better Health' programme illustrates the potential of combined public-private campaigns. At local level, positive dietary changes are achievable through a range of initiatives in the community. The success of interventions appeared to differ according to the targeted outcome. Increases in F\&V consumption were obtained in eighteen studies in several settings. By contrast, on the basis of limited evidence from four studies, none of the interventions achieved a reduction in red meat intake. Findings were mixed for reduction in fat intake (seventeen studies) and increase in fibre intake (five studies). In contrast to an earlier review that found that healthy eating interventions aimed at $F \& V$ were 'less

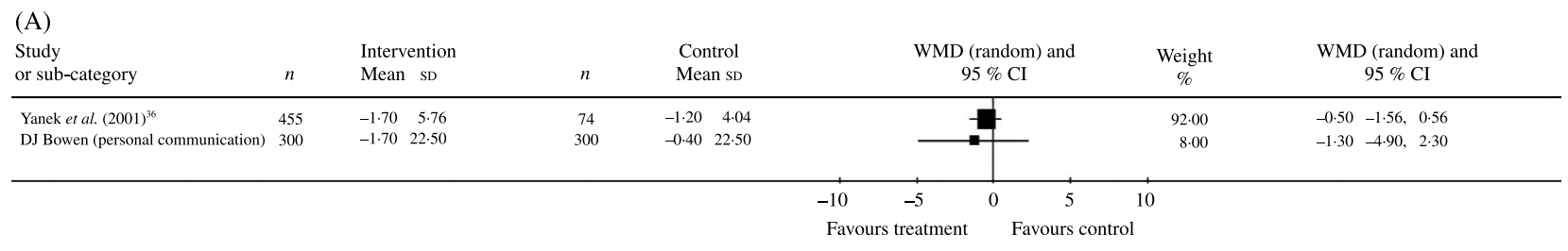

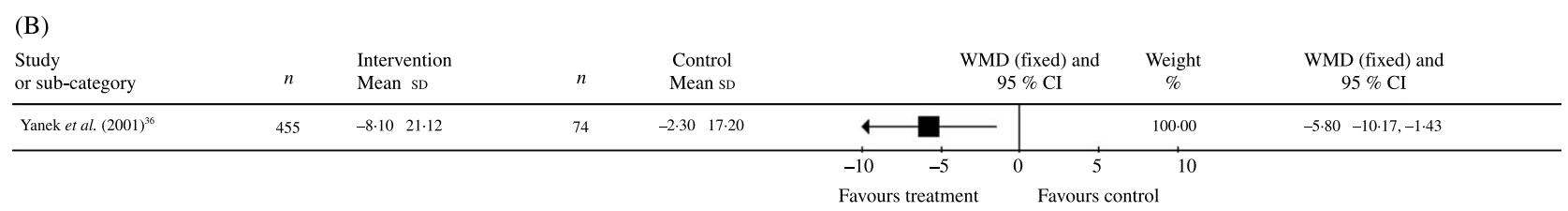

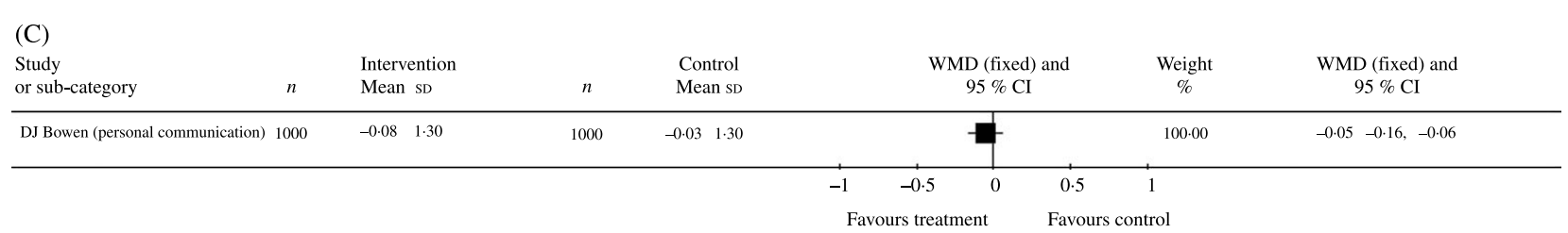

Fig. 7. Church studies: fat intake. (A) Fat intake (\% energy), (B) fat intake (g/d), (C) fat intake (fat scores). WMD, weighted mean difference. 


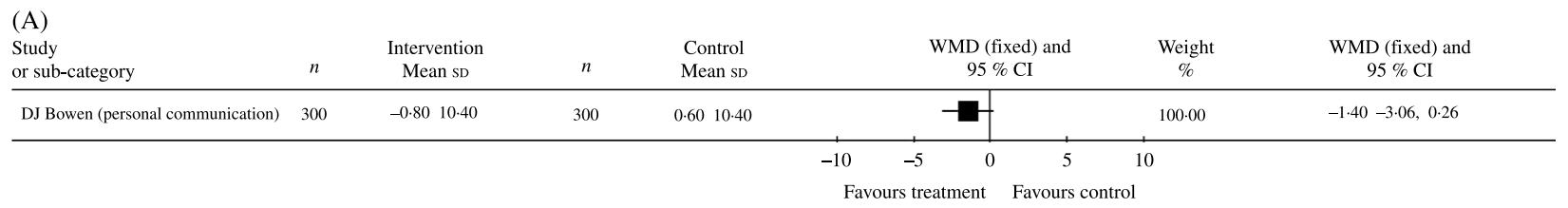

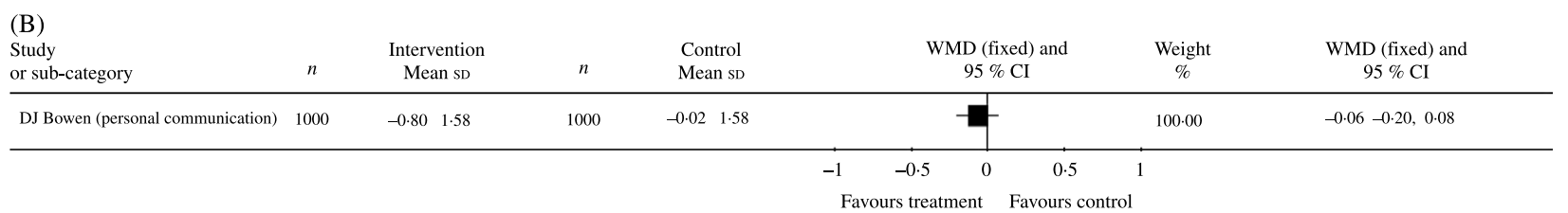

Fig. 8. Church studies: fibre intake. (A) Fibre intake (g/1000 kcal), (B) fibre intake (fibre score). WMD, weighted mean difference.

effective ${ }^{3}$ we found that promotion of $F \& V$ intake was a positive food-based intervention that was more likely to achieve health gain than interventions aimed at other dietary targets.

\section{Limitations of the review}

We limited our literature searches to electronic databases and websites. Although we also contacted experts in the field and searched reference lists of the relevant studies, we might have missed some relevant studies. We excluded many potential evaluation studies because the research design was not adequately described in terms of selection and use of controls, sampling in before-and-after studies, methods for measuring outcomes, and short duration. We may have missed some potentially includable studies because we were unable to obtain grey literature reports in the time available.

In some cases a study was described in more than one published paper. We tried to obtain all papers reporting methodology and outcome assessment but we might have missed some data. This is particularly relevant in the assessment of the use of a theoretical framework in the studies. When this information was missing in the study description we could only say with certainty that authors did not report it.

Community-based interventions are often complex and multifactorial and difficult to evaluate by conventional randomized controlled trials. To allow for this, we set wide criteria for the inclusion of studies, but this inevitably means that many of the evaluations had somewhat weak designs, which may have resulted in an overestimate or underestimate of the effect of the intervention. Because so few studies were randomized controlled trials we were limited in the amount of meta-analysis we could carry out, and were also unable to carry out any formal analysis to check for evidence of publication bias.

\section{Nature and quality of included studies}

We set out to systematically identify and summarize the available evidence on community- and population-level programmes for diet-based chronic disease prevention. Of the forty-one studies in healthy adult populations and communities (predominantly towns, and places of work and worship), most (twenty-five studies, $68 \%$ ) were conducted in North America and reflect recent US trends in health promotion, with a focus on $\mathrm{F} \& \mathrm{~V}$ consumption. Many studies were based in the general population or community settings (eighteen of the forty-one) and in workplaces (seventeen). A limited number of studies (five) targeted members of religious organizations. We found only one study that evaluated a health promotion programme in a supermarket environment.

We found only a limited number of interventions that were outside the three common settings: neighbourhood, places of work and places of worship. This is despite the fact that we employed broad inclusion criteria, which were not limited to controlled trials and required no more than one measured food or diet-related outcome relevant to cancer prevention. We found only two evaluations of populationwide programmes, one in the USA and one in Wales. We did not, for example, find any evaluation of Norwegian food policy, despite its high profile in the $1980 \mathrm{~s}^{55}$.

The great variety in study design, target population, types of intervention activities and outcome measurement tools made the evaluation of effectiveness a difficult process. The majority of worksite and church-based studies were clusterrandomized trials (ten of the seventeen worksite studies and three of five of church-based studies). Most communitywide studies used relatively weak study designs: twelve of

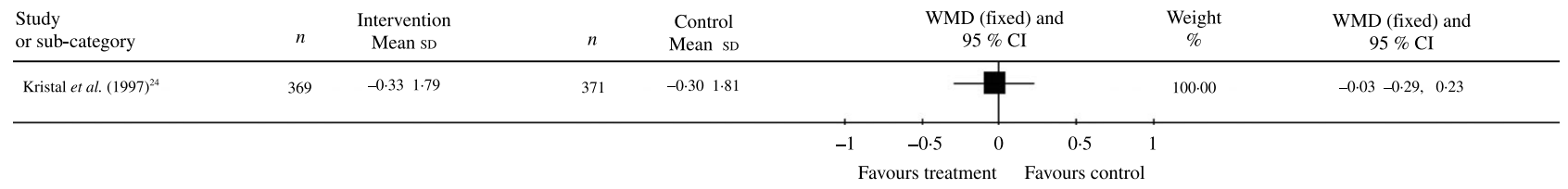

Fig. 9. Retail and supermarket studies. Fruit and vegetable intake (servings per d). WMD, weighted mean difference. 
the eighteen were non-randomized studies with a comparison group and five studies used before-and-after evaluations. The studies varied greatly in quality of reporting, and the inadequate description of methodology made interpretation difficult. Only five studies used objective methods for outcome assessment; three studies reported milk sales data from supermarkets; one study reported cafeteria sales data and one study assessed the weight of F\&V consumed in a worksite cafeteria. Most of the studies relied on a selfreported assessment of dietary behaviours.

Twenty-six of forty-one included studies implemented multifactorial programmes aiming at complex behavioural change which included not only dietary habits but also physical activity and smoking. Sixteen of those twenty-six studies reported at least one positive intervention effect in the assessed dietary outcomes. The remaining fifteen studies focused on one central dietary objective, such as an increase of F\&V consumption. Three of those studies implemented a simple intervention (for example, offering low-fat meals in worksite cafeterias) but most of them employed multiple intervention activities. Twelve of fifteen studies with one central dietary objective found a positive intervention effect on dietary habits of the study participants.

\section{Implications for the design of effective interventions}

It was not possible to draw firm conclusions about the effectiveness of individual intervention components because so many of the interventions employed a complex combination of strategies. We could not identify a clear association of intervention components with dietary behaviour changes. Common intervention activities in the studies that were classified as successful were as follows:

(a) printed materials including posters, brochures, flyers, self-help guides, educational sessions and presentations;

(b) events such as health fairs and contests;

(c) cafeteria point-of purchase displays and promotions, healthy choice offers on menus and in vending machines;

(d) mass media approaches including programmes and advertising on national or local television, radio and newspapers.

Implementing organizational, environmental and policy changes in addition to intervention activities in worksites and communities contributed to effectiveness. In common with the earlier reviews (Table 3) we found that interventions that lasted for a longer time (more than 1 year) were more successful.

Worksites and churches seem to be promising settings for the implementation of health promotion programmes. These settings possess several characteristics that make them suitable for health education activities. They are relatively contained communities that provide a context for peer support, positive peer pressure and leadership, as well as opportunities for implementation of special activities and lasting changes relating to provision of food and drink.

Changes in food supply and composition. The present systematic review does not extend to the impact of generic changes in the food supply, or food composition. If such foods are important sources of nutrients with health significance, and they are affordable, there can be a major influence on population nutrition. For example, household food purchase data show that the introduction of palatable polyunsaturated fat spread and the shift towards vegetable cooking oil during the 1980s contributed to a large and rapid increase in the dietary PUFA:SFA ratio in Great Britain ${ }^{56}$.

Cost effectiveness. Although we included health economics data in our list of outcome measure to be collected, none of the papers that we reviewed reported any costeffectiveness analysis. While it is intuitive to assume that community programmes incur lower costs per individual reached by the programme, we are unable to comment further on the comparative cost effectiveness of community programmes as opposed to individual interventions.

Theoretical framework. One of the most discussed aspects of health promotion interventions is the extent to which a theoretical framework contributes to success. Although earlier reviews have made a strong case for the importance of a theoretical framework ${ }^{3}$, we were unable to confirm this importance in the present review. More than half of the included studies reported the use of one or more theories as a basis for intervention activities. Most commonly used were the transtheoretical model of behaviour change (stages of change theory), social learning theory (social cognitive theory), and community organization strategies. In a majority of the studies there was a lack of detailed information about the links between theoretical framework(s) and specific activities, and the extent to which activities were based on those theories. We did not find any evidence from the information available that theory-based interventions were more effective than others.

\section{Implications for research}

A major problem in the assessment of healthy eating interventions continues to be the limitations of dietary intake measurement tools. We were unable to compare the outcomes of many of the evaluations that we reviewed because the authors used a variety of different scoring systems to measure dietary change. Although it is 10 years since an earlier review called for more reliable methods to be developed ${ }^{3}$, this remains a problem.

We were frustrated by the lack of clarity with respect to the nature of interventions, the methods employed for their evaluation, and the findings of many of the papers we reviewed. Both researchers and journal editors have a role to play in ensuring adequate and clear reports of research. Models for research reports are readily available, including systematic guidelines for reports of clinical trials ${ }^{57}$ and cohort studies (including before-and-after studies) ${ }^{58}$.

We did not find any papers in several important areas, particularly the commercial and social marketing of healthy foods, including: pricing strategies; structural interventions including regulation and planning of retail provision and transport links; and national campaigns to promote healthy 
eating. In addition, little attention has been paid to the possibilities of employing technology such as point-of-sale data capture to monitor dietary habits, provide feedback, and evaluate in-store health promotion activities.

\section{Conclusions}

Evidence of effectiveness was strongest for interventions intended to increase F\&V consumption. Further evaluations are needed of the effects of nationwide campaigns, advertising and marketing strategies. The studies included in the present review, although selected for the quality of their design and execution, were generally poorly reported. Valuable dietary changes are obtained in the relatively shortterm studies reviewed here but may not be sustained in the long term, especially in the context of the multiple influences on food behaviour in urban societies. Many of the wider determinants of food behaviour are pervasive, and the interventions evaluated here are campaigns fought with limited resources over a limited time span. The effects that we have identified are small. However, since all these interventions aimed to reach groups, and in some cases very large groups, the reach is potentially very wide. The cost effectiveness of such strategies remains to be evaluated.

\section{Acknowledgements}

The present study was funded by the World Cancer Research Fund. We are grateful to Deborah Bowen, Timothy Dobbins, Judy Simpson, Glorian Sorensen and Ingrid Steenhuis who provided additional data for us. Helen Moore provided invaluable help with preparing the manuscript.

\section{References}

1. Key TJ, Schatzkin A, Willett WC, Allen NE, Spencer EA \& Travis RC (2004) Diet, nutrition and the prevention of cancer. Public Health Nutr 7, 187-200.

2. Glanz K, Sorensen G \& Farmer A (1996) The health impact of worksite nutrition and cholesterol intervention programs. Am J Health Promot 10, 453-470.

3. Roe L, Hunt P, Bradshaw H \& Rayner M (1997) Health Promotion Interventions to Promote Healthy Eating in the General Population: a Review. London: HEA.

4. Fletcher A \& Rake C (1998) Effectiveness of Interventions to Promote Healthy Eating in Elderly People Living in the Community: a Review. London: HEA.

5. Peersman G, Harden A \& Oliver S (1998) Effectiveness of Health Promotion Intervention in the Workplace: a Review. London: HEA.

6. Van Teijlingen E, Wilson BJ, Barry N, Ralph A, McNeil G, Graham W \& Campbell D (1998) Effectiveness of Interventions to Promote Healthy Eating in Pregnant Women and Women in Childbearing Age: a Review. London: HEA.

7. White M, Carlin L \& Rankin J (1998) Effectiveness of Interventions to Promote Healthy Eating in People from Minority Ethnic Groups: a Review. London: HEA.

8. Brug J, Campbell M \& van Assema P (1999) The application and impact of computer-generated personalized nutrition education: a review of the literature. Patient Educ Couns 36, $145-156$.
9. Ciliska D, Miles E, O’Brien MA \& Turl C (2000) Effectiveness of community-based interventions to increase fruit and vegetable consumption. J Nutr Educ 32, 341-352.

10. Bowen DJ \& Beresford SA (2002) Dietary interventions to prevent disease. Annu Rev Public Health 23, 255-286.

11. Janer G, Sala M \& Kogevinas M (2002) Health promotion trials at worksites and risk factors for cancer. Scand $J$ Work Environ Health 28, 141-157.

12. Brunner EJ, Thorogood M, Rees K \& Hewitt G (2005) Dietary interventions for reducing cardiovascular risk. Cochrane Database of Systematic Reviews CD002128. http://www. mrw.interscience.wiley.com/cochrane/clsysrev/articles/ CD002128/frame.html

13. Higgins JPT \& Green S (2005) Cochrane Handbook for Systematic Reviews of Interventions 4.2.5, section 8.5.2.10 (updated May 2005). http://www.cochrane.org/resources/ handbook/hbook.htm (accessed 10 October 2006).

14. Brownson RC, Smith CA, Pratt M, Mack NE, JacksonThompson J, Dean CG, Dabney S \& Wickerson JC (1996) Preventing cardiovascular disease through community-based risk reduction: the Bootheel Heart Health project. Am J Public Health 86, 206-213.

15. Croft JB, Temple SP, Lankenau B, Heath GW, Macera CA, Eaker ED \& Wheeler FC (1994) Community intervention and trends in dietary fat consumption among black and white adults. J Am Diet Assoc 94, 1284-1290.

16. Cheadle A, Psaty M, Diehr P, Koepsell T, Wagner E, Curry S \& Kristal A (1995) Evaluating community-based nutrition programs: comparing grocery store and individual-level survey measures of program impact. Prev Med 24, 71-79.

17. Foerster SB, Kizer KW, Disogra LK, Bal DG, Krieg BF \& Bunch KL (1995) California's "5 a Day - for Better Health" campaign: an innovative population-based effort to effect large-scale dietary change. Am J Prev Med 11, 124-131.

18. Glasgow RE, Terborg JR, Hollis JF, Severson HH \& Boles SM (1995) Take Heart: results from the initial phase of work-site wellness program. Am J Public Health 85, 209-216.

19. Glasgow RE, Terborg JR, Strycker LA, Boles SM \& Hollis JF (1997) Take Heart II: replication of a worksite health promotion trial. J Behav Med 20, 143-161.

20. Turner LW, Sutherland M, Harris GJ \& Barber M (1995) Cardiovascular health promotion in north Florida AfricanAmerican churches. Health Values 19, 3-9.

21. Dubois A, Strychar IM, Champagne F, Leblanc MP \& Tremblay C (1996) The effect of a worksite cafeteria program on employees' dietary fat intakes. J Can Diet Assoc 57, 98-102.

22. Sorensen G, Stoddard A, Peterson K, Cohen N, Hunt MK, Stein E, Palombo R \& Lederman R (1999) Increasing fruit and vegetable consumption through worksites and families in the treatwell 5-a-day study. Am J Public Health 89, 54-60.

23. Sorensen G, Thompson B, Glanz K, Feng Z, Kinne S, DiClemente C, Emmons K, Heimendinger J, Probart C \& Lichtenstein E (1996) Work site-based cancer prevention: primary results from the Working Well Trial. Am J Public Health 86, 939-947.

24. Kristal AR, Goldenhar L, Muldoon J \& Morton RF (1997) Evaluation of a supermarket intervention to increase consumption of fruits and vegetables. Am J Health Promot 11, 422-425.

25. Perlmutter CA, Canter DD \& Gregoire MB (1997) Profitability and acceptability of fat- and sodium-modified hot entrees in a worksite cafeteria. J Am Diet Assoc 97, 391-395.

26. Reger B, Wootan MG \& Booth-Butterfield S (1999) Using mass media to promote healthy eating: a community-based demonstration project. Prev Med 29, 414-421. 
27. Reger B, Wootan MG \& Booth-Butterfield S (2000) A comparison of different approaches to promote communitywide dietary change. Am J Prev Med 18, 271-275.

28. Reger B, Wootan MG, Booth-Butterfield S \& Smith H (1998) 1\% or less: a community-based nutrition campaign. Public Health Rep 113, 410-419.

29. Buller DB, Morrill C, Taren D, Aickin M, Sennott-Miller L, Buller MK, Larkey L, Alatorre C \& Wentzel TM (1999) Randomized trial testing the effect of peer education at increasing fruit and vegetable intake. J Natl Cancer Inst 91, $1491-1500$.

30. Campbell MK, Demark-Wahnefried W, Symons M, et al. (1999) Fruit and vegetable consumption and prevention of cancer: the Black Churches United for Better Health Project. Am J Public Health 89, 1390-1396.

31. Campbell M, Tessaro I, DeVellis B, Benedict S, Kelsey K, Belton L \& Sanhueza A (2002) Effects of a tailored health promotion program for female blue-collar workers: health works for women. Prev Med 34, 313-323.

32. Fries EA, Ripley JS, Fugueiredo MI \& Thompson B (1999) Can community organization strategies be used to implement smoking and dietary changes in a rural manufacturing work site? J Rural Health 15, 413-420.

33. O'Loughlin JL, Paradis G, Gray-Donald K \& Renaud L (1999) The impact of a community-based heart disease prevention program in a low-income, inner-city neighborhood. Am $J$ Public Health 89, 1819-1826.

34. Tilley BC, Glanz K, Kristal AR, Hirst K, Li S, Vernon SW \& Myers R (1999) Nutrition intervention for high-risk auto workers: results of the Next Step Trial. Prev Med 28, 284-292.

35. Beresford SA, Thompson B, Feng Z, Christianson A, McLerran D \& Patrick DL (2001) Seattle 5 a Day worksite program to increase fruit and vegetable consumption. Prev Med 32, 230-238.

36. Yanek LR, Becker DM, Moy TF, Gittelsohn J \& Koffman DM (2001) Project joy: faith based cardiovascular health promotion for African American women. Public Health Rep 116, 68-81.

37. Stables GJ, Subar AF, Patterson BH, Dodd K, Heimendinger J, Van Duyn MA \& Nebeling L (2002) Changes in vegetable and fruit consumption and awareness among US adults: results of the 1991 and 19975 A Day for Better Health Program surveys. $J$ Am Diet Assoc 102, 809-817.

38. Elliot DL, Goldberg L, Duncan TE, Kuehl KS, Moe EL, Breger RK, DeFrancesco CL, Ernst DB \& Stevens VJ (2004) The PHLAME firefighters' study: feasibility and findings. Am $J$ Health Behav 28, 13-23.

39. Huot I, Paradis G \& Ledoux M; Quebec Heart Health Demonstration Project Research Group (2004) Effects of the Quebec Heart Health Demonstration Project on adult dietary behaviours. Prev Med 38, 137-148.

40. Resnicow K, Campbell MK, Carr C, McCarty F, Wang T, Periasamy S, Rahotep S, Doyle C, Williams A \& Stables G (2004) Body and Soul - a dietary intervention conducted through African-American churches. Am J Prev Med 27, 97-105.

41. Van Assema P (1994) Results of the Dutch community project 'Healthy Bergeyk'. Prev Med 23, 394-401.

42. Albright CL (1996) Nutritional epidemiology: methods and innovations used in a central European community-based program. Nutrition 12, 386-387.
43. Van Wechem SN, Van Assema P, Brug J, Kistemaker C, Riedstra M, Hardeman W \& Lowik MR (1997) Results of a community-based campaign to reduce fat intake. Nutr Health 11, 207-218.

44. Tudor-Smith C, Nutbeam D, Moore L \& Catford J (1998) Effects of the Heartbeat Wales programme over five years on behavioural risks for cardiovascular disease: quasi-experimental comparison of result from Wales and a matched reference area. BMJ 316, 818-822.

45. Lupton BS, Fonnebo V \& Sogaard AJ (2003) The Finnmark Intervention Study: is it possible to change CVD risk factors by community-based intervention in an Arctic village in crisis? Scand J Public Health 31, 178-186.

46. Wrigley N, Warm D \& Margetts B (2003) Deprivation, diet, and food-retail access: findings from the Leeds 'food deserts' study. Environ Plan A 35, 151-188.

47. Holdsworth M, Raymond MT \& Haslam C (2004) Does the Heartbeat Award scheme in England result in change in dietary behaviour in the workplace? Health Promot Int 19, 197-204.

48. Lassen A, Thorsen AV, Trolle E, Elsig M \& Ovesen L (2004) Successful strategies to increase the consumption of fruits and vegetables: results from the Danish ' 6 a day' Work-site Canteen Model Study. Public Health Nutr 7, 263-270.

49. Ronda G, Van Assema P, Candel M, Ruland E, Steenbakkers M, Van Ree J \& Brug J (2004) The Dutch Heart Health community intervention 'Hartslag Limburg': results of an effect study at individual level. Health Promot Int 19, 21-31.

50. Steenhuis I, Van Assema P, Van Breukelen G, Glanz K, Kok G \& De Vries H (2004) The impact of educational and environmental interventions in Dutch worksite cafeterias. Health Promot Int 19, 335-343.

51. Dunt D, Day N \& Pirkis J (1999) Evaluation of a communitybased health promotion program supporting public policy initiatives for a healthy diet. Health Promot Int 14, 317-327.

52. Simpson JM, Oldenburg B, Owen N, Harris D, Dobbins T, Salmon A, Vita P, Wilson J \& Saunders JB (2000) The Australian National Workplace Health Project: design and baseline findings. Prev Med 31, 249-260.

53. Cook C, Simmons G, Swinburn B \& Stewart J (2001) Changing risk behaviours for non-communicable disease in New Zealand working men - is workplace intervention effective? N Z Med J 114, 175-178.

54. Bowen DJ, Beresford SA, Vu T, Feng Z, Tinkler L, Hart A Jr, Christensen AL, McLerran D, Satia-Abouta J \& Campbell M (2004) Baseline data and design for a randomized intervention study of dietary change in religious organizations. Prev Med 39, 602-611.

55. Milio N (1981) Promoting health through structural change: analysis of the origins and implementation of Norway's farmfood-nutrition policy. Soc Sci Med 15, 721-734.

56. National Food Survey Committee (1991) Household Food Consumption and Expenditure 1990 Annual Report of the National Food Survey Committee. London: Ministry of Agriculture, Fisheries and Food.

57. Moher D, Schulz KF \& Altman DG (2001) The CONSORT statement revised recommendations for improving the quality of reports of parallel-group randomised trials. Lancet 357, $1191-1194$.

58. Stroup DF, Berlin JA, Morton SC, Olkin I, Williamson GD, Rennie D, Moher D, Becker BJ, Sipe TA \& Thacker SB (2000) Meta-analysis of observational studies in epidemiology: a proposal for reporting. Meta-analysis of Observational Studies in Epidemiology (MOOSE) group. JAMA 283, 2008-2012. 